Research Article

\title{
Experimental and Analytical Study on the Vibration Performance of U-Shaped Steel-Concrete Composite Hollow Waffle Slab
}

\author{
Xi Zhang $\mathbb{D}^{1}{ }^{1}$ Qiming Wang, ${ }^{2}$ Yousan Wang, ${ }^{3}$ and Qing $\mathbf{L i}^{1}$ \\ ${ }^{1}$ School of Mechanics and Civil Engineering, China University of Mining and Technology, Beijing 100083, China \\ ${ }^{2}$ China Aerospace Construction Group Co, Ltd., Beijing 100071, China \\ ${ }^{3}$ State Forestry Planning and Design Institute of Forest Products Industry, Beijing 100009, China
}

Correspondence should be addressed to Xi Zhang; 360341566@qq.com

Received 12 November 2019; Revised 14 January 2020; Accepted 31 January 2020; Published 27 February 2020

Academic Editor: Mahmoud Bayat

Copyright (c) $2020 \mathrm{Xi}$ Zhang et al. This is an open access article distributed under the Creative Commons Attribution License, which permits unrestricted use, distribution, and reproduction in any medium, provided the original work is properly cited.

The large-span floor system being lightweight with low frequency and low damping is prone to suffer severe vibration under human excitations. In this research, the vibration performance of an innovative large-span U-shaped steel-concrete composite hollow waffle $(\mathrm{CHW})$ slab was studied based on field testing and theoretical analysis. First, the modal properties of $\mathrm{CHW}$ slab including mode shapes, frequencies, and damping ratio were captured by on-site tests and validated by the finite element method, indicating the $\mathrm{CHW}$ slab is a low-frequency floor system with a low damping ratio. Second, the vibration responses of CHW slab under heel-drop and jumping excitations were studied considering the impacts of spatial position, tester number, and activity types. Third, the CHW slab shows excellent vibration serviceability proved by the frequency, accelerations, and human perceptions threshold with the current codes. Meanwhile, the paper gives appropriate threshold values for the CHW slab under impulsive excitation. Finally, the natural frequency formula for the CHW slab derived by the Rayleigh-Ritz energy method agrees well with the measurements.

\section{Introduction}

Owing to the growing demand for large space and flexible layout of the buildings, large-span floor structures have been widely used in gymnasiums, open buildings, and industrial buildings. The floor height and self-weight increase significantly with the rising spans in traditional floors, such as reinforced concrete (RC) floors, steel-concrete composite floors [1,2], prestressed concrete floors [3], and waffle slab [4], yielding high material usage and poor economic efficiency. Researchers have studied new types of long-span floor systems with the good structural performance [5-7]. The CHW slab is an innovative floor system (Figure 1) containing the RC slab, upper beams, lower beams, and web members. The three-dimensional floor system presents excellent mechanical performance, where the upper beams and slab are in pressure, and the lower beams are in tensile when suffering vertical load. The U-shaped steel plates that wrap at the side and bottom of the lower beams enhance the tensile strength, hence enlarging the span length. Additionally, the U-shaped steel plates can be used as formwork during construction. The ample openings between web numbers supply space to accommodate ducts and pipes without compromising the story height; meanwhile, the floor selfweight and earthquake action decrease. The upper and lower beams are connected by large shear stiffness web members with a small height-width ratio (less than 1), which makes the floor form good integrity.

Lightweight, low frequency, and low damping are the main properties of large span floor systems. Thus, the CHW slab is prone to vibrate largely under excitations. Typical vibration sources are vehicles on nearby roads, large machinery in nearby construction sites, and human activities. Human activities are the most common ones, among which 


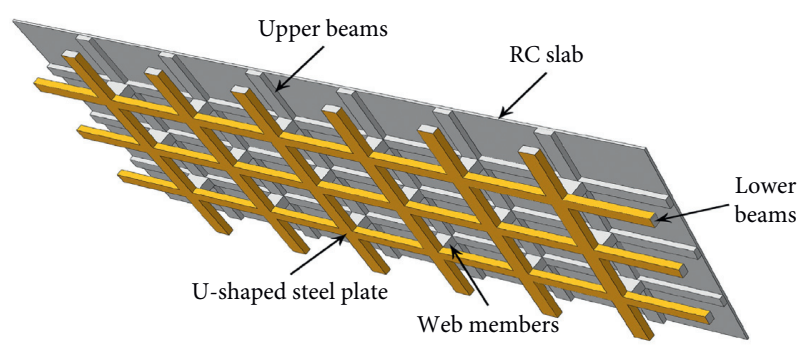

FIGURE 1: U-shaped steel-concrete composite hollow waffle floor.

heel-drop and jumping excitations are more drastic. Resonance happens when the frequency of human activity approaches the floor fundamental frequency $[8,9]$. Excessive vibration makes people feel uncomfortable or even panic [10]. Once the vibration serviceability problem occurs, the maintenance cost is huge [11]. Thus, it means to study the floor vibration response due to human activities before putting the floor into use.

Over the past decades, the vibration performances under human-induced excitations for various kinds of floors were studied [12-14], yielding several acceptable design codes [15-20] for vibration evaluation and control. Generally, the frequency threshold and amplitude threshold are used for vibration evaluation. The frequency threshold is simple at the design stage, and the codes give theoretical formulas for frequency calculation, assuming that the beams or plates are simply supported. However, prediction accuracy decreases as the complexity of the floors increases, with ribbed slabs, composite materials, and variable boundary conditions [21]. The amplitude threshold is more accurate as the value directly relates to the vibration response.

Researchers have either used on-site tests or finite element analysis (FEA) to study floor vibrations. FEA is accurate to obtain mode shapes and frequencies of the floor; however, it is difficult to simulate all sorts of human activities and time-consuming [22]. Meanwhile, the vibration response largely depends on the damping, and no empirical damping ratio is recommended for the new floor. On-site tests are effective. The static tests $[23,24]$ have shown that the CHW slab has large rigidity with good bearing capacity. However, large-span floor systems are governed by serviceability requirements rather than strength requirements [25]. Few studies [26] regarding the dynamic properties of the CHW slab and none on-site heel-drop and jumping tests have been conducted. Therefore, both on-site tests and theoretical analyses were conducted in this paper to study the dynamic behavior of the CHW slab.

The aims of this research are as follows:

(i) To obtain the accurate damping ratio, frequencies, and mode shapes of CHW slab from the ambient vibration tests (AVT)

(ii) To capture the dynamic behavior of $\mathrm{CHW}$ slab under heel-drop and jumping tests considering the influence of spatial position, tester number, and activity type

(iii) To appraise the vibration serviceability of the CHW slab with the ISO maximum 10 s RMS acceleration and AISC peak acceleration and provide appropriate threshold values for $\mathrm{CHW}$ slab

(iv) To derive the natural frequencies formula for the CHW slab based on the Rayleigh-Ritz energy method

\section{Description of Study Floor}

Field tests were conducted on the Dzong commercial office building (Figure 2) to study the vibration response of the $\mathrm{CHW}$ slab. The as-built building located in Beijing is a twintower building with a skirt. The CHW slab is adopted as a floor hanging garden with open-air restaurants and coffee houses on the roof floor of the skirt building. The 1.4-meterhigh floor has a rectangular plan of $27 \mathrm{~m}$ by $36 \mathrm{~m}$, supported by perimeter frames spaced at $9 \mathrm{~m}$. The floor consists of $80 \mathrm{~mm}$ thick RC slab and multiple equal-spaced (about $2.4 \mathrm{~m}$ ) hollow beams; the latter includes the upper beams, lower beams, and 0.7-meter-high web members. Shear studs connect the lower beams and U-shaped steel plates as a whole. Design details of the floor are shown in Figure 3. The side and bottom steel plates of the U-shaped steel plates are connected by high strength bolts initially under construction; then, the floor system was poured together. During the test, the structural frame was completed before the installation of any nonstructural components. The on-site tests were divided into the ambient vibration tests and humaninduced tests as follows.

\section{Modal Parameter Characterization}

3.1. Ambient Vibration Tests. AVT is a powerful and accurate approach for the estimation of the modal properties of the long-span floor system [27]. Hence, AVT was conducted on the CHW slab. Pretest analyses were performed to determine suitable measurement points (MPs) for the AVT. Simulated mode shapes were studied using the finite element program ABAQUS (version 6.14) [28]. Thirty-five uniform grids of MPs spaced at $4.5 \mathrm{~m}$ were chosen based on the auto modal assurance criterion (MAC) values of the simulated mode sets to ensure that the mode shapes separate from each other and show accurate modal properties.

The dynamic response of the $\mathrm{CHW}$ slab was recorded by using five magnetoelectric accelerometers (TST 126, Test Electron, Jingjiang, Jiangsu, China) with a bandwidth ranging from 0.25 to $100 \mathrm{~Hz}$, a sensitivity of $3 \mathrm{~V} / \mathrm{g}$, and a mass of $0.80 \mathrm{~kg}$. A sixteen-channel data acquisition system (TST3827E, Test Electron, Jingjiang, Jiangsu, China) was used to record the response signals. Figure 4 shows the measurement locations and testing devices. All the MPs were accurately positioned and numbered with chalk. For the limitation of accelerometers, nine sets were taken for the measurements. Each set had one mutual reference sensor (large dot in Figure 4(a)) near the midspan of the floor and four roving sensors (small dot in Figure 4(a)), where the last set had only three roving sensors. The duration for each set was 300 seconds with a sampling frequency of $200 \mathrm{~Hz}$. 


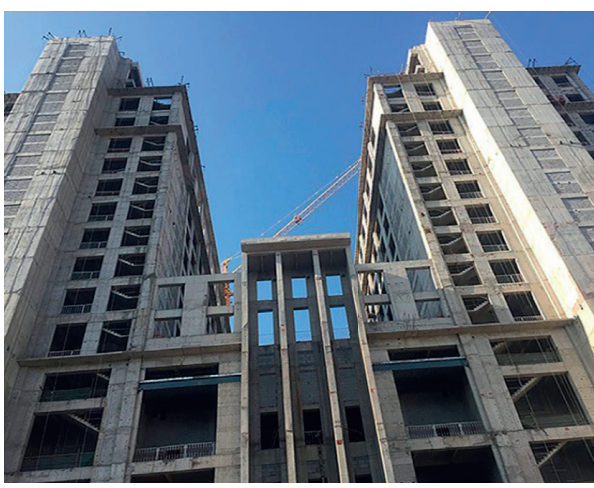

(a)

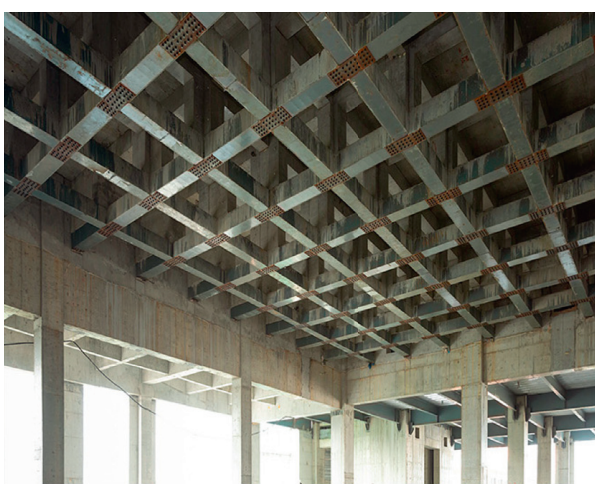

(b)

FIgure 2: Photos of the tested building: (a) overview of the building; (b) on-site photo of the CHW slab system.

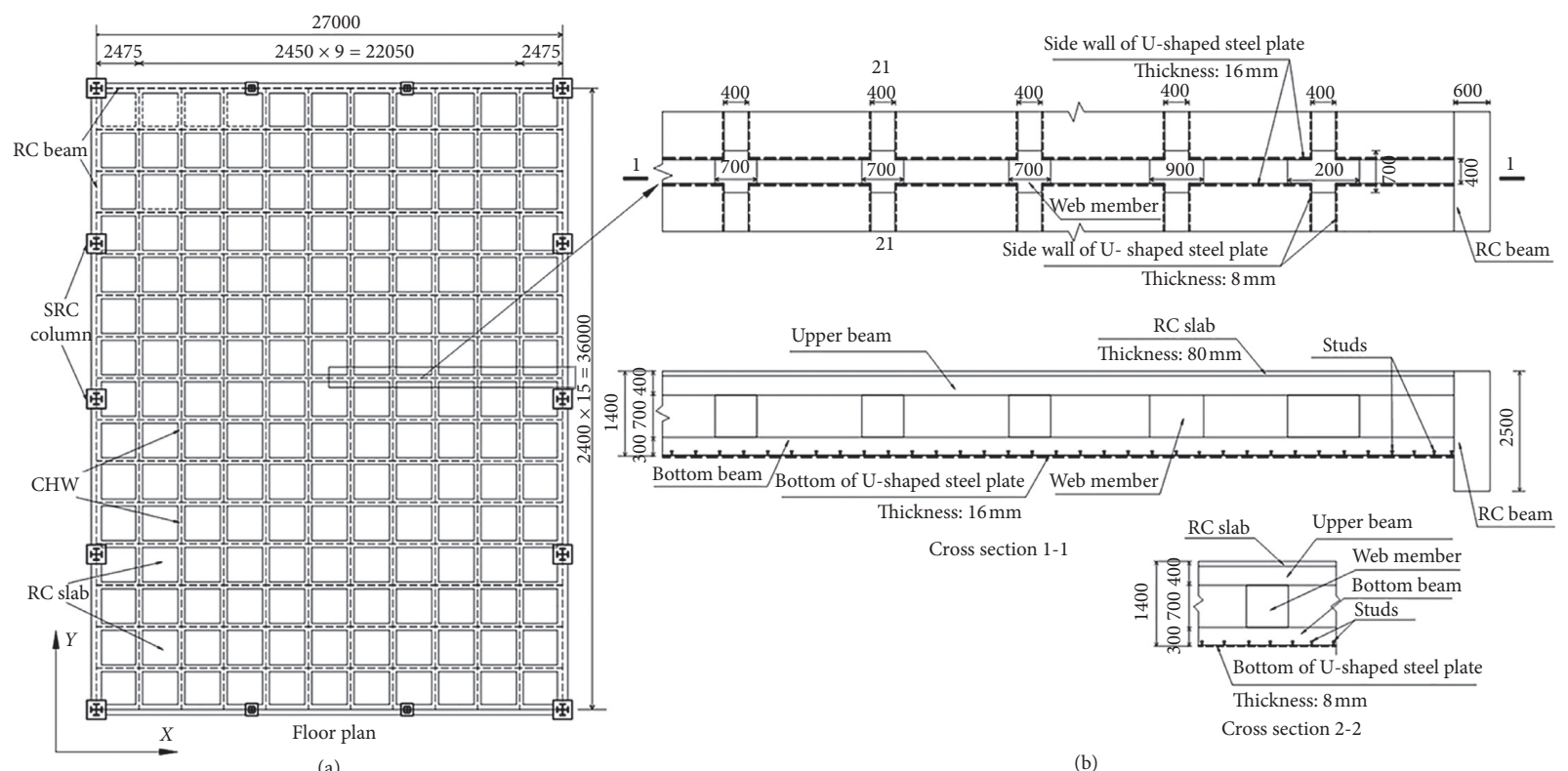

(a)

(b)

Figure 3: The CHW slab: (a) overview structural layout of the floor; (b) detailed layout of the floor.

3.2. Modal Parameter Characterization. The measurements were filtered to eliminate the static component below $0.5 \mathrm{~Hz}$ and the burrs caused by mixed noises above $40 \mathrm{~Hz}$ [29]. The enhanced frequency domain decomposition (EFDD) technique was used to conduct operational modal analysis (OMA) [30, 31]. The EFDD overcomes the limitations of frequency-domain decomposition with accurate damping ratios, as implemented by TSTMP (Test Electron, Jingjiang, Jiangsu, China). Initially, the single degree-of-freedom (SDOF) equivalent power spectral density function (Bell function) was calculated around the peak value using the fast Fourier transform (FFT) of the measurements, where the peak value was the damped frequency and the left singular vector was the corresponding mode shape. The bell function was designated by these singular values, where the corresponding singular vectors had a high MAC value (greater than 0.9) with the mode shape vector [32]. Next, the inverse FFT was performed on the bell function to obtain the autocorrelation curve (Figure 5). Then, the associated damping ratio was calculated by the logarithmic decay method from the autocorrelation curve [33]. The first three modes were considered, each set of the nine test groups had one correlation function for each mode, the natural frequency and the corresponding damping ratio of each mode from the nine group EFDD analysis were averaged as the final values.

AISC DG11 suggests that the damping ratio of the steelconcrete composite floor without furniture and nonstructural components should be $2 \%$. CCIP-016 suggests that the damping ratio of the steel-concrete composite floor without decoration surface should be between $0.8 \%$ and $1.5 \%$. ISO 10137 suggests that the damping ratio of the bare steelconcrete composite floor connected by shear bolts should be $1.8 \%$. The damping ratio of the first three modes obtained from the EFDD method is $2.35 \%, 1.86 \%$, and $1.34 \%$, respectively. The damping ratio of the first mode of the $\mathrm{CHW}$ 


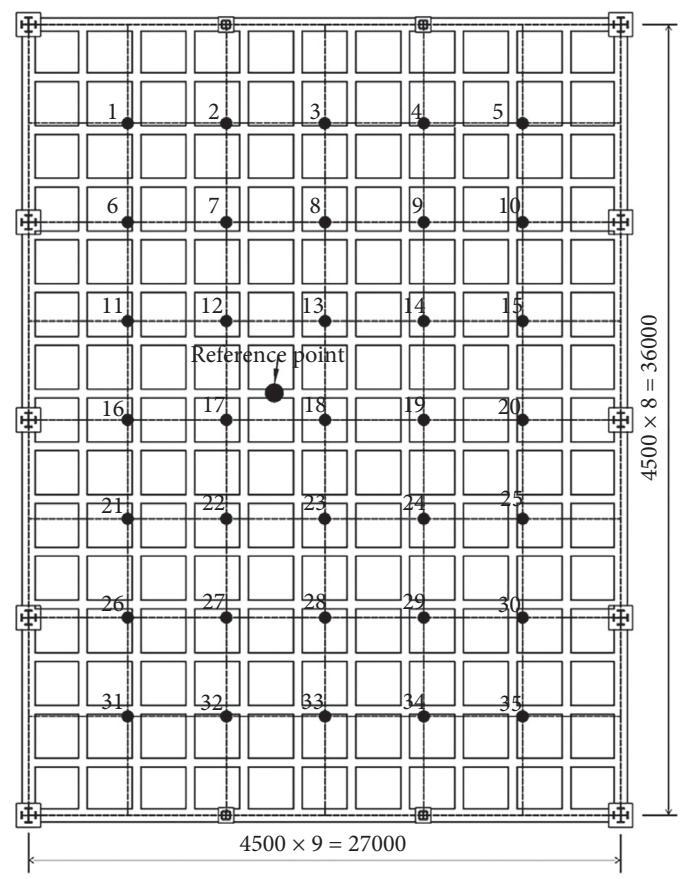

(a)

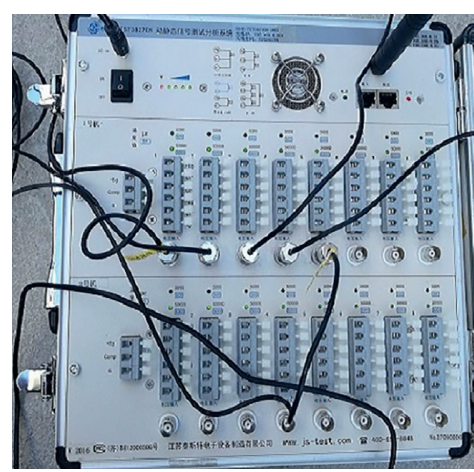

(b)

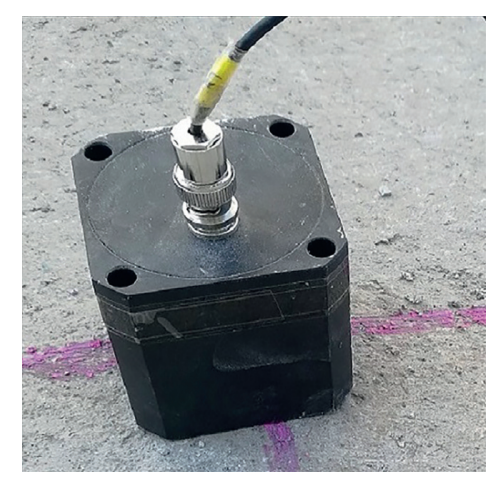

(c)

Figure 4: Testing devices and measurement locations: (a) measurement locations, (b) dynamic acquisition instrument, and (c) accelerometer.

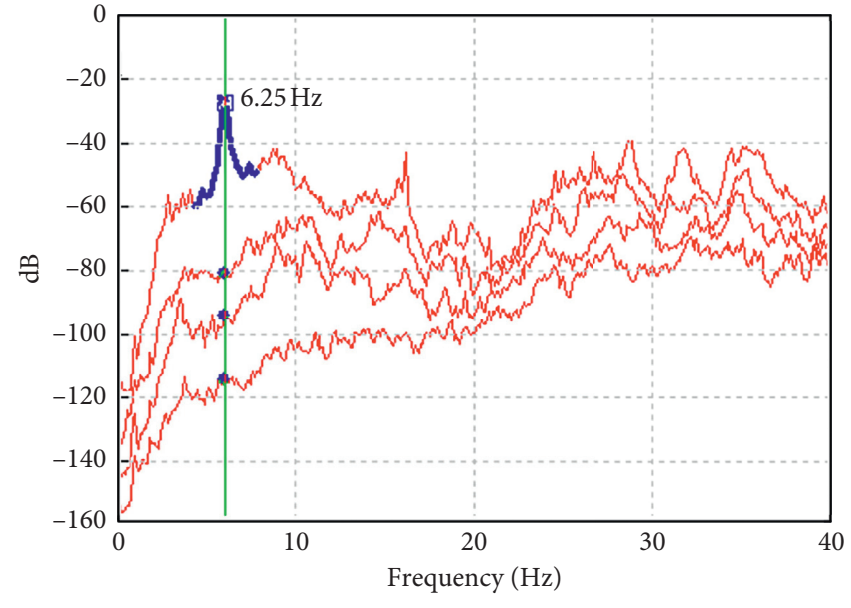

(a)

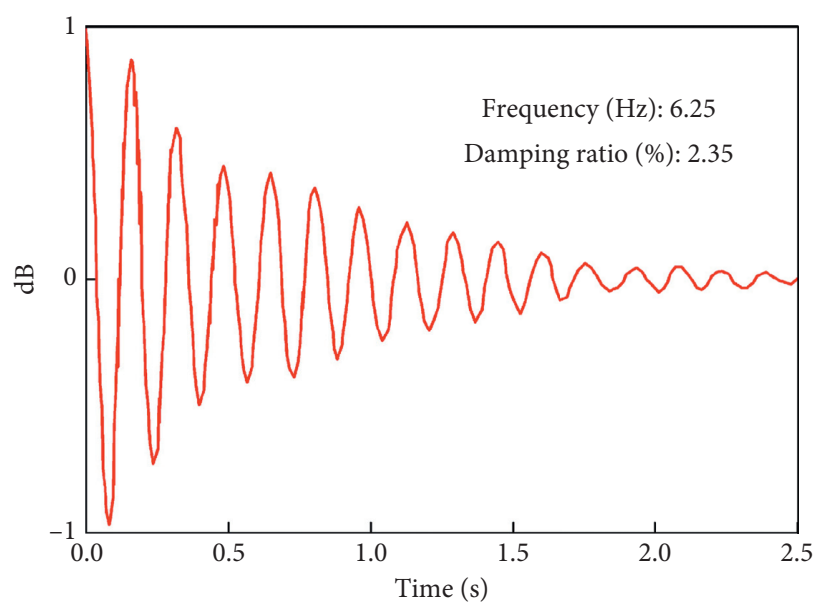

(b)

FIGURE 5: EFDD modal analysis: (a) singular values of the decomposed power spectral density matrices and the BF identification; (b) normalized SDOF autocorrelation curve of the first mode.

slab is slightly larger than the above codes. Meanwhile, the fundamental frequency of the floor is $6.25 \mathrm{~Hz}$, indicating that the CHW slab is a low-frequency floor system with a low damping ratio.

ABAQUS FEA program was used to compare the modal parameters with OMA results. The concrete was simulated by eight-node linear brick elements with reduced integration and hourglass control (C3D8R). Four-node elements with reduced integration and hourglass control (S4R) were used for the simulation of U-shaped steel plates. The concrete parts were merged with the boundary conditions fixing at the bottoms of the columns. The U-shaped plates were tied to the concrete. The global size of $0.1 \mathrm{~m}$ was chosen for accurate calculation; moreover, the RC slab was divided into three meshes along the thickness to ensure the accuracy of the analysis.

The normalized relative frequency difference (NRFD) and MAC are used for comparisons between simulated and measured results. The eigenfrequencies from simulations and measurements were compared by using NRFD values expressed as follows: 


$$
\mathrm{NRFD}=\frac{\left|f_{i}^{\text {sim }}-f_{j}^{\exp }\right|}{f_{j}^{\exp }},
$$

where $f_{i}^{\text {sim }}$ is the $i$ th simulated eigenfrequency and $f_{j}^{\exp }$ is the $j$ th measured eigenfrequency. MAC values were employed to quantify the similarity in mode shapes. The MAC value is described as

$$
\text { MAC }=\frac{\left|\left(\Phi_{i}^{\operatorname{sim}}\right)^{T}\left(\Phi_{j}^{\exp }\right)\right|^{2}}{\left(\Phi_{i}^{\operatorname{sim}}\right)\left(\Phi_{i}^{\operatorname{sim}}\right)\left(\Phi_{j}^{\exp }\right)^{T}\left(\Phi_{j}^{\exp }\right)},
$$

where $\Phi_{i}^{\text {sim }}$ is the $i$ th simulated mode shape and $\Phi_{j}^{\exp }$ is the $j$ th measured mode shape. The MAC value falls between 0 and 1 , where 1 implies a perfect correlation between the two mode shapes.

Table 1 shows the mode shapes, frequencies, the NRFD, and MAC values from OMA and FEA. The mode shapes show that the floor behaves like a plate in free vibration. Specifically, the first mode is one single waveform in both $x$ direction and $y$ direction; the second mode is one waveform associated with $x$ direction and two waveforms associated with $y$ direction; the third mode is one waveform associated with $x$ direction and three waveforms associated with $y$ direction. The frequencies of the first three modes obtained from FEA are slightly smaller than OMA with the maximum NRFD value smaller than $5 \%$. The MAC values of the EFDD and FEA methods are very close to 1 where spectral peaks occur. Specifically, the value is $0.951,0.942$, and 0.936 for the first three modes, which provides further evidence of the vibration modes and suggests a good quality of data.

\section{Human-Induced Vibration Tests and Discussion}

Note that heel-drop is recommended by AISC for frequency prediction, and jumping is the most vigorous human excitation [34]. Heel-drop and the jumping tests were conducted on the floor center (at A3). Five accelerometers were placed with an adjacent distance of $6 \mathrm{~m}$ (Figure 6(a)). First, single-person heel-drop and jumping tests were undertaken for many times, taking 5 effective acceleration time history curves and recording the human perception during the tests. Then, the multiperson $(2,3,4$, and 5$)$ heel-drop and jumping tests were performed by adding one more person each time (Figure 6) to study the influence of multiperson excitation.

The peak acceleration and the root mean square (RMS) acceleration are widely used for vibration assessment. AISC Design Guide 11 recommends the peak acceleration to evaluate floor vibrations. To consider the influence of duration and frequency, IS0 10137 adopts the RMS acceleration which can be calculated according to

$$
a_{\mathrm{RMS}}=\sqrt{\frac{1}{T} \int_{0}^{T} a_{w}^{2}(t) \mathrm{d} t},
$$

where $\alpha_{w}(t)=$ frequency weighted acceleration; $T$ = duration of the response; and $t=$ time. In this paper, the peak acceleration and the peak 1s RMS suggested by ISO 10137 panic criterion are used to evaluate the vibration responses caused by human activities.

4.1. Heel-Drop Tests. Heel-drop tests were first conducted by a person weighing $70 \mathrm{~kg}$. Figure 7 shows the typical acceleration time history curves and the corresponding spectrum curves. Heel-drop excitation is transient response. Although the tester was requested to heel-drop at the same height $(80 \mathrm{~mm})$, the peak acceleration varies. The spectrum curve shows the constant maximum peak amplitudes at the fundamental frequency of $6.25 \mathrm{~Hz}$ despite the diversity of amplitudes, indicating that heel-drop excitations generate the most significant energy at the fundamental frequency.

The most dramatic responses happen at the floor center (Figure 8). The average maximum acceleration and 1s RMS acceleration are $30.62 \mathrm{~mm}^{2} \mathrm{~s}^{-1}$ and $5.11 \mathrm{~mm}^{2} \mathrm{~s}^{-1}$, respectively. The floor vibration response gradually weakens from the center to the edge. When the distance to the floor center $\left(d_{0}\right)$ increases from $6 \mathrm{~m}$ (at A2) to $12 \mathrm{~m}$ (at A1), the peak accelerations are $23.02 \%$ and $6.27 \%$ of the floor center. The layout of the CHW slab influences the acceleration distribution. Larger stiffness in the short span causes weaker vibration response. Particularly, when $d_{0}=6 \mathrm{~m}$, the peak accelerations at location A2 (along the short span) and A4 (along the long span) are $23.02 \%$ and $30.62 \%$ of the central floor. The same conclusions can be reached from the peak $1 \mathrm{~s}$ RMS accelerations.

As shown in Table 2, the average peak accelerations of heel-drop tests at floor center with $n(n=1,2.3,4.5)$ participants are $30.64 \mathrm{~mm}^{2} \mathrm{~s}^{-1}, 37.33 \mathrm{~mm}^{2} \mathrm{~s}^{-1}, 43.79 \mathrm{~mm}^{2} \mathrm{~s}^{-1}$, $47.78 \mathrm{~mm}^{2} \mathrm{~s}^{-1}$, and $51.76 \mathrm{~mm}^{2} \mathrm{~s}^{-1}$. The measurements show that more participants lead to a larger floor vibration response. Although the testers were requested to heel-drop simultaneously with a height of $80 \mathrm{~mm}$ following the music beat, it is harder for the testers to heel-drop at the same time, height, and frequency with larger group sizes. The fastest growth occurs when the tester number increases from one to two. However, the growth slows down as the tester number rises.

Damping determines the dissipation of structural energy and significantly influences the amplitude and duration of the floor vibration response. The damping ratio of a lowdamped floor system can be determined using the timedomain logarithmic decay method as follows:

$$
\xi=\frac{1}{2 \pi \mathrm{k}} \ln \frac{A_{1}}{A_{i}},
$$

where $A_{1}$ and $A_{i}$ are the maximum peak accelerations and the $i$ th peak accelerations. The paper takes $i=8$ for the calculation of the damping ratio under impulsive excitations. The measurements were filtered to pass frequency exceeding 1.5 to 2 times the fundamental frequency before calculation. As a floor with a fundamental frequency of $6.25 \mathrm{~Hz}$, only the frequency below $10 \mathrm{~Hz}$ is kept.

Table 3 indicates that a larger $d_{0}$ causes a smaller damping ratio; nevertheless, the decline of damping ratio occurs much more gently compared to the acceleration. Specifically, the minimum damping ratio caused by single- 
TABLe 1: Comparation between OMA and FEA of the CHW slab.

Mode 1

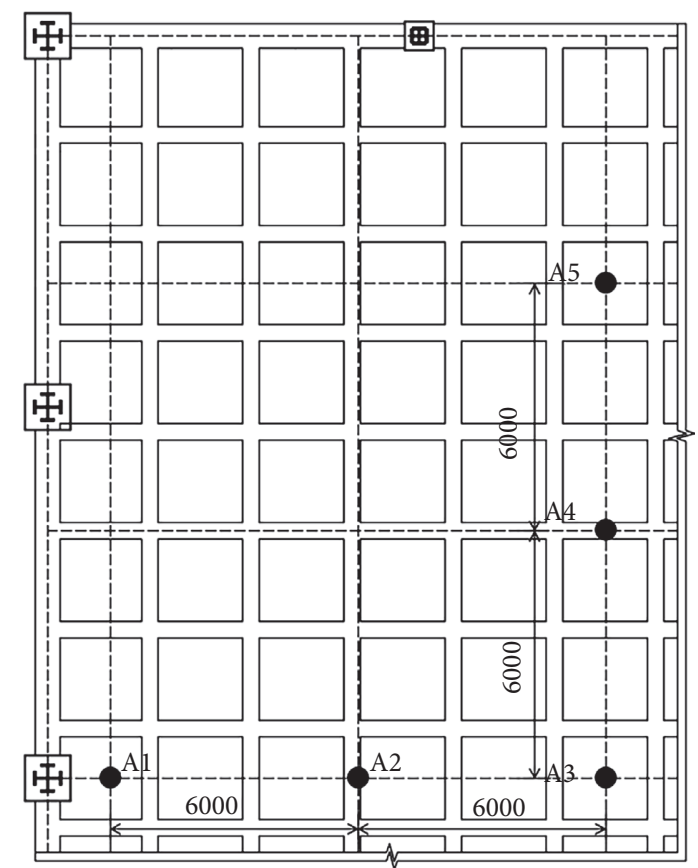

(a)
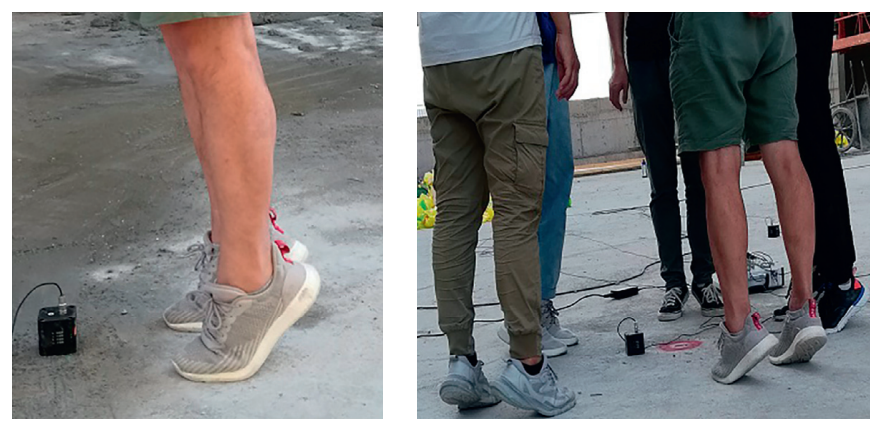

(b)

(c)

Figure 6: Continued. 


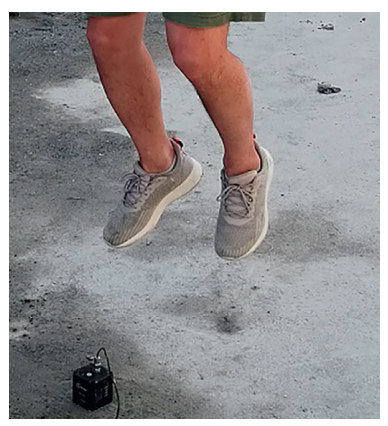

(d)

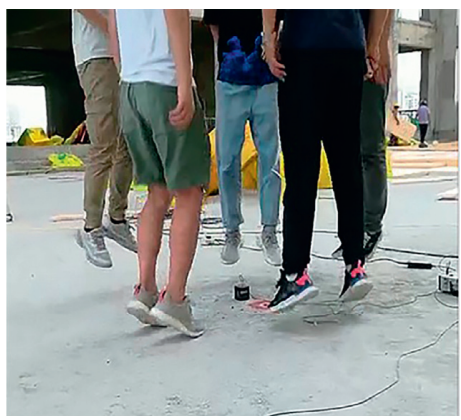

(e)

FIGURE 6: Human-induced vibration tests: (a) measurement locations; (b) single-person heel-drop tests; (c) five-persons heel-drop tests; (d) single-person jumping tests; and (e) five-persons jumping tests.

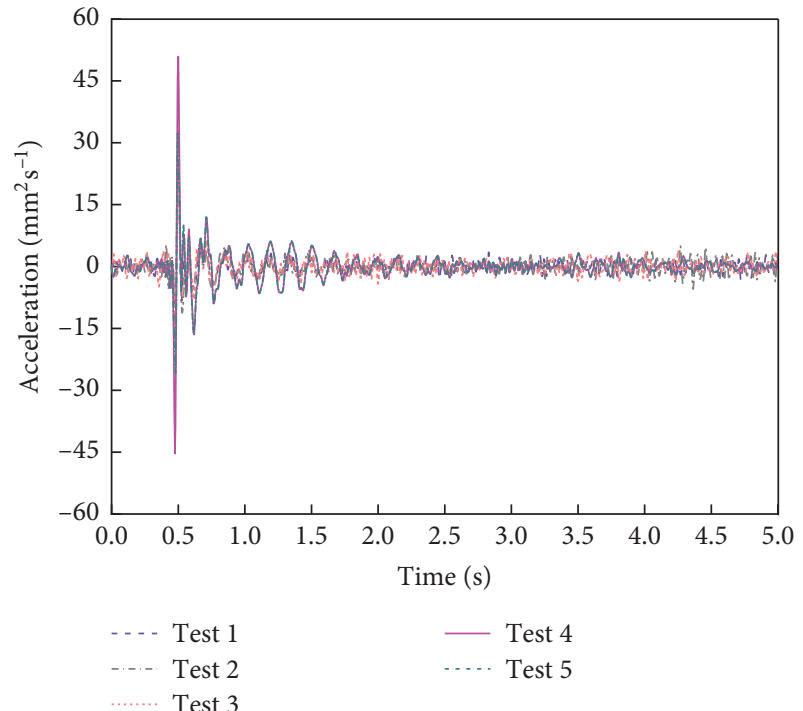

(a)

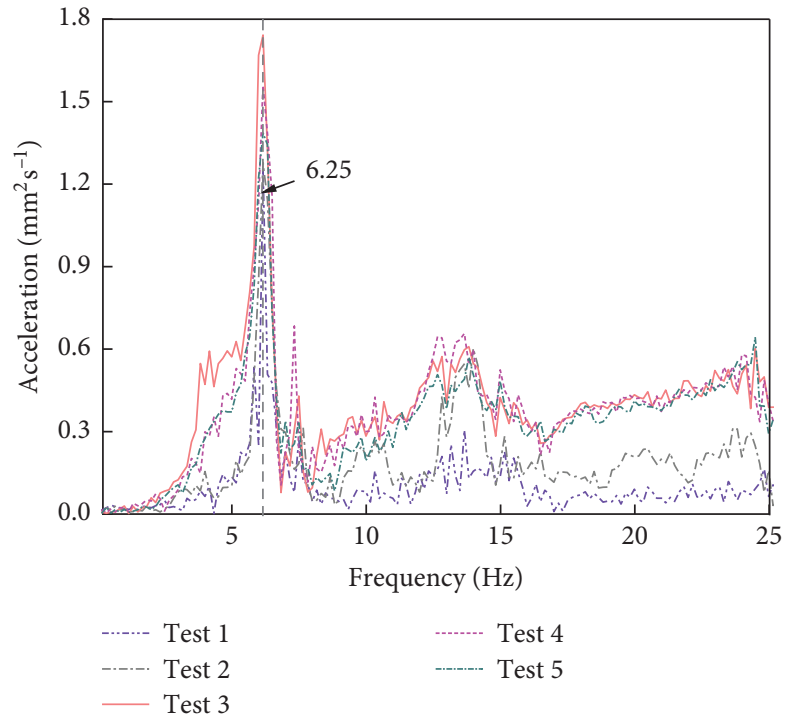

(b)

Figure 7: Typical time-domain curve and frequency-domain curve induced by single-person heel-drop tests: (a) acceleration responses; (b) corresponding power spectrum.

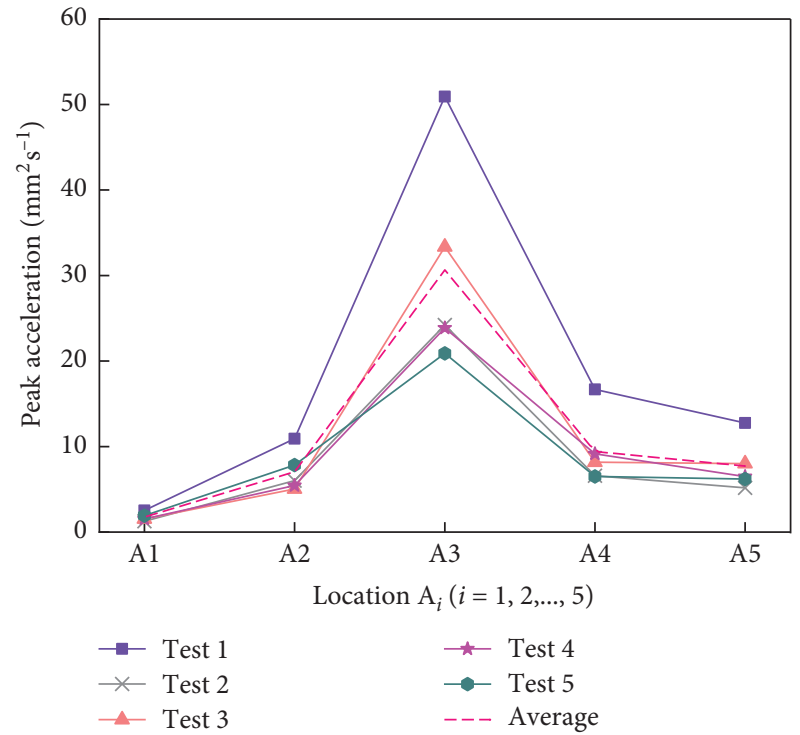

(a)

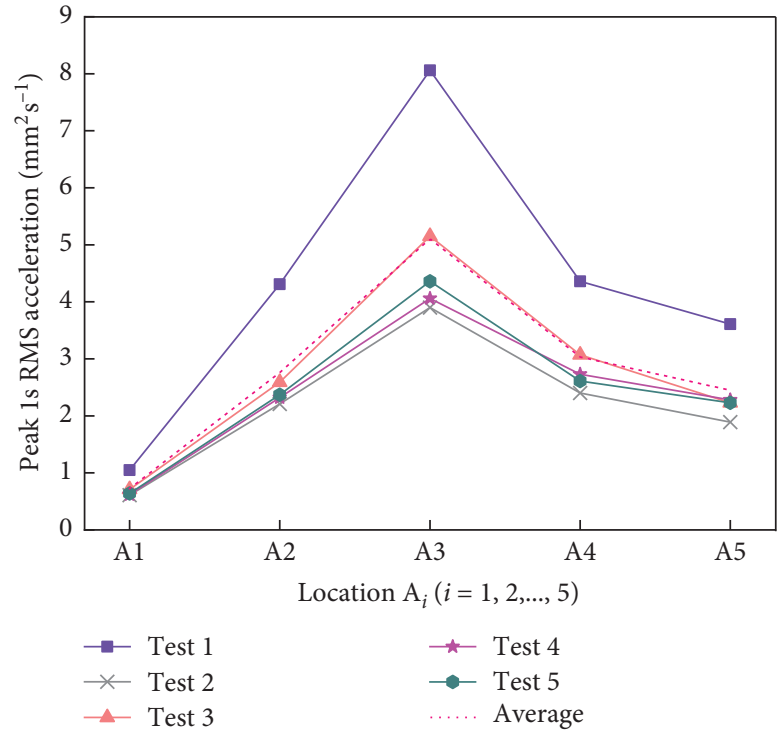

(b)

FIGURE 8: Acceleration distributions under single-person heel-dropping tests: (a) peak acceleration distributions; (b) peak $1 \mathrm{~s}$ RMS acceleration distributions. 
TABLe 2: The peak acceleration due to multiperson heel-drop tests.

\begin{tabular}{lccccc}
\hline Acceleration $\left(\mathrm{mm}^{2} \mathrm{~s}^{-1}\right)$ & A1 & A2 & A3 & A4 & A5 \\
\hline 1 person & 1.76 & 7.05 & 30.64 & 9.42 & 7.72 \\
2 persons & 1.82 & 8.18 & 37.33 & 8.36 \\
3 persons & 3.63 & 13.20 & 43.79 & 17.75 & 13.88 \\
4 persons & 3.69 & 14.45 & 47.78 & 18.02 & 14.07 \\
5 persons & 3.67 & 16.70 & 51.76 & 18.75 & 16.83 \\
\hline
\end{tabular}

TABle 3: Damping ratio (\%) owing to multiperson heel-drop tests.

\begin{tabular}{lccccc}
\hline Damping ratio (\%) & A1 & A2 & A3 & A4 & \\
\hline 1 person & 2.52 & 2.73 & 2.91 & 3.04 & 2.85 \\
2 persons & 2.55 & 2.86 & 3.16 & 2.92 & 3.02 \\
3 persons & 2.67 & 2.96 & 3.22 & 3.08 & 2.83 \\
4 persons & 2.72 & 2.99 & 3.22 & 3.13 & 2.95 \\
5 persons & 2.85 & 3.09 & 3.05 \\
\hline
\end{tabular}

person heel-drop tests at location A1 is still $87.69 \%$ of A3 (floor center); meanwhile, the peak acceleration is merely $6.27 \%$ of $\mathrm{A} 3$. With the same $d_{0}$, the damping ratio of the long span is slightly larger than the short span. The damping ratio increases slightly with the rising group sizes. Particularly, the damping ratio of $n(n=2,3,4,5)$ person heel-drop tests increases by $4.54 \%, 8.73 \%, 10.65 \%$, and $10.79 \%$, respectively, at the floor center compared to one person.

4.2. Jumping Tests. Jumping activity is the most violent human-induced excitation. Thus, it is beneficial to carry out jumping tests for a comprehensive vibration evaluation of the $\mathrm{CHW}$ slab. Typical acceleration responses and the corresponding spectrum curves caused by a person (weighing $70 \mathrm{~kg}$ ) jumping are seen in Figure 9. The spectrum curve shows that the maximum peak amplitudes occur at the fundamental frequency of $6.25 \mathrm{~Hz}$, indicating that both heeldrop and jumping tests are accurate in predicting the natural frequency of the floor.

Figure 10 shows that the vibration response caused by person jumping tests is much more severe than heel-drop tests. Specifically, the average maximum acceleration and maximum $1 \mathrm{~s}$ RMS acceleration due to jumping are $74.196 \mathrm{~mm}^{2} \mathrm{~s}^{-1}$ and $11.348 \mathrm{~mm}^{2} \mathrm{~s}^{-1}$ at the central floor, which is 2.42 and 2.22 times the value of heel-drop tests. Consistent with heel-drop tests, the floor vibration response decreases as $d_{0}$ increases. The vibration decreases sharply along the short span and gently along the long span. The acceleration amplitude is not linearly increasing with the rising group sizes (Table 4 ). For instance, the acceleration owing to $n(n=2,3,4,5)$ persons jumping is $1.28,1.47,1.65$, and 1.79 times of the value under a person.

The force peak amplitude per person decreased with increasing numbers of people and even synchronization within a crowd took place [35]. A particular example is the research of Ebrahimpour [36]. He conducted jumping tests in a large number of people in the crowd for $2 \mathrm{~Hz}$ periodic load; when the tester number increased from one to four, the load amplitude per person decreased from 110 psf to 80 psf. Periodic jumping models can be stimulated by the Fourier series. Ellis and Ji [37] gave the first three Fourier coefficients for the dynamic load factor (DLF) by the research of groups of people (up to 64 people) jumping rhythmically. The data showed that the DLF values decrease with the rising tester numbers. Guo [38] studied the crowd jumping (up to 48 people) using $3 \mathrm{D}$ motion capture technique, and he indicated that the DLFs largely depend on the jumping frequency. He compared the DLF curves of $2.0 \mathrm{~Hz}$ and $2.5 \mathrm{~Hz}$ test cases with the results from Ellis. The DLF values under single-person jumping excitations are nearly the same, with the values of $1.61,0.94$, and 0.44 for the first three harmonics. However, when the tester numbers reached five, the DLF values decrease sharply. Specifically, the study at $2 \mathrm{~Hz}$ jumping tests is much smaller, with the values of $0.97,0.4$, and 0.20 for the first three harmonics, and the values are $1.16,0.61$, and 0.22 for the first three harmonics at $2.5 \mathrm{~Hz}$. However, even the crowd jumps were conducted following a music beat with a constant frequency $(2 \mathrm{~Hz})$ and height $(400 \mathrm{~mm})$, and perfect synchronization is unlikely to be achieved.

The damping ratio obtained from multiperson jumping tests. Table 5 shows the same tendency as heel-drop tests. Nevertheless, the damping ratio is $8 \%$ higher than the value of heel-drop at the floor center. The damping ratio of $n$ $(n=2,3,4,5)$ person jumping tests at the floor center increases by $2.10 \%, 3.64 \%, 3.76 \%$, and $4.25 \%$ compared to single-person tests. However, the growth is smaller than the heel-drop.

4.3. Summary and Discussion. As mentioned above, frequency is the natural characteristics of the CHW slab, the value being constant despite the excitations. Jumping excitation is more severe, and the acceleration is twice more than heel-drop with the same person at the floor center. The vibration response increases notably with the rising numbers. The vibration response largely depends on the boundary condition and structural layout of the floor system. In short, the vibration response weakens from the center to the edge. With the same distance from the central floor, larger vibration happens along the long span. 


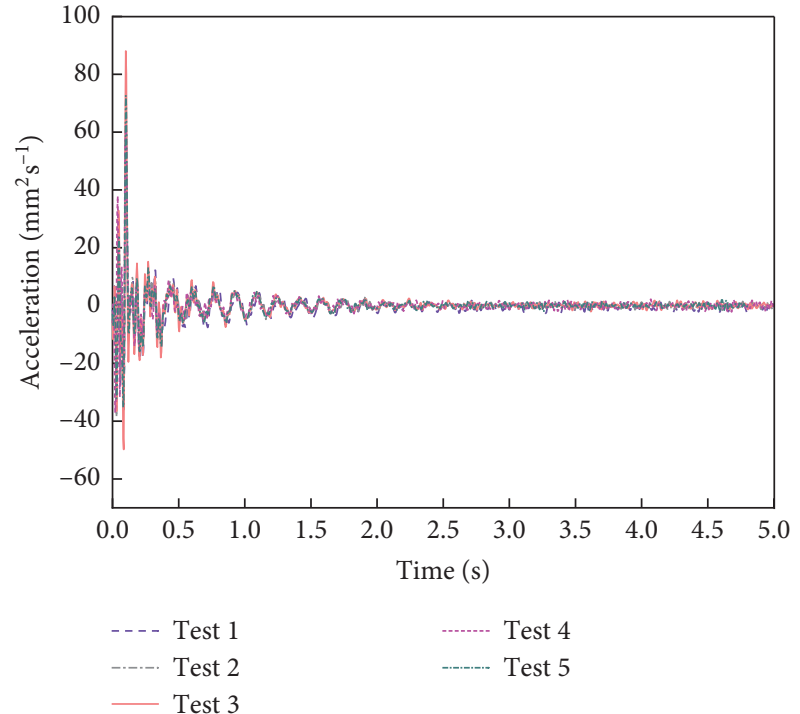

(a)

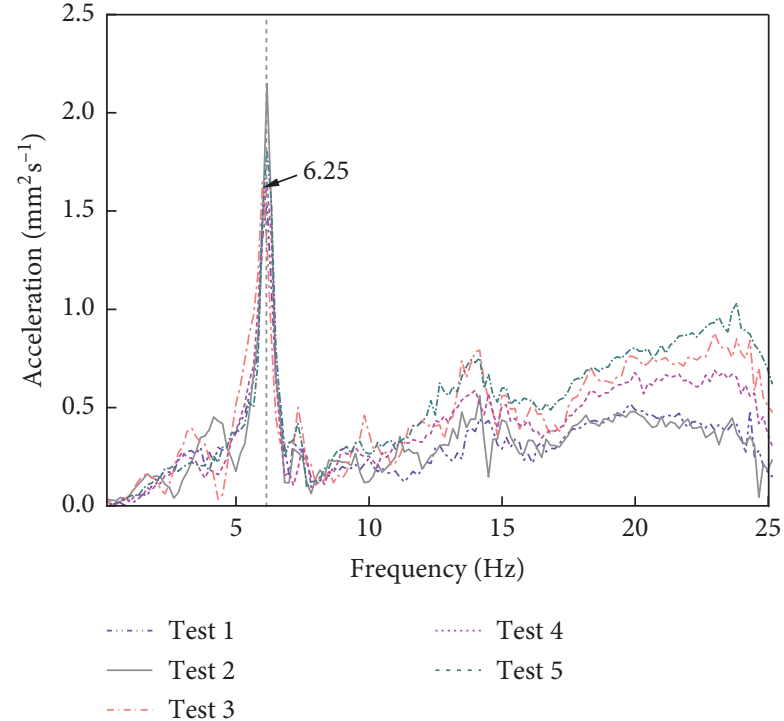

(b)

Figure 9: Typical time-domain curve and frequency-domain curve induced by single-person jumping tests: (a) acceleration responses; (b) corresponding frequency responses.

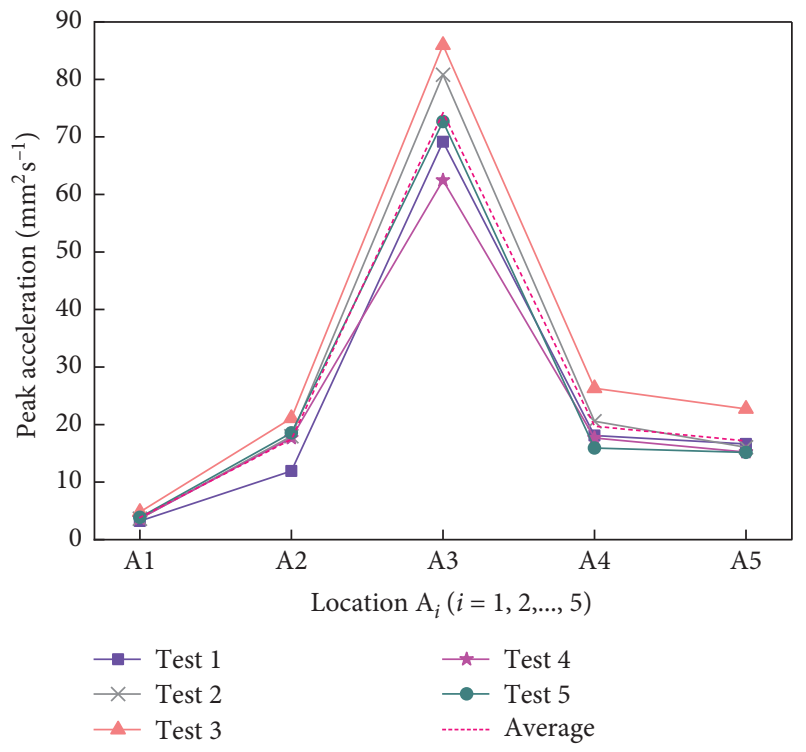

(a)

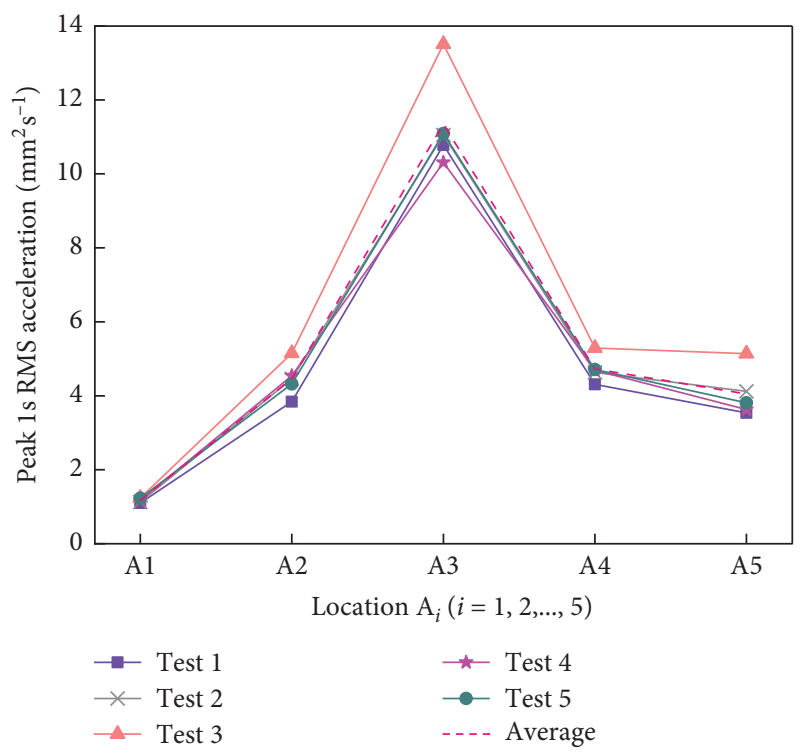

(b)

FIGURE 10: Acceleration distributions under single-person jumping tests: (a) peak acceleration distributions; (b) peak $1 \mathrm{~s}$ RMS acceleration distributions.

TABLE 4: The peak accelerations due to multiperson jumping tests.

\begin{tabular}{lccccc}
\hline Acceleration $\left(\mathrm{mm}^{2} \mathrm{~s}^{-1}\right)$ & A1 & A2 & A3 & A4 & A5 \\
\hline 1 person & 3.84 & 17.44 & 74.20 & 19.71 & 17.16 \\
2 persons & 6.05 & 23.25 & 94.84 & 24.35 & 20.63 \\
3 persons & 8.11 & 31.92 & 109.11 & 34.40 & 28.31 \\
4 persons & 8.30 & 32.25 & 122.66 & 36.47 & 29.42 \\
5 persons & 8.32 & 33.71 & 133.14 & 38.14 & 29.86 \\
\hline
\end{tabular}

TABLE 5: Damping ratio obtained from multiperson jumping tests.

\begin{tabular}{lccccc}
\hline Damping ratio (\%) & A1 & A2 & A3 & A4 & A5 \\
\hline 1 person & 2.77 & 2.92 & 3.24 & 3.04 & 2.93 \\
2 persons & 2.78 & 2.97 & 3.31 & 3.09 & 2.99 \\
3 persons & 2.88 & 3.03 & 3.36 & 3.18 & 3.04 \\
4 persons & 2.92 & 3.15 & 3.37 & 3.23 & 3.08 \\
5 persons & 2.94 & 3.18 & 3.38 & 3.24 & 3.11 \\
\hline
\end{tabular}


The damping ratio owing to a person jumping is 1.08 times the value of heel-drop, showing the increasing amplitude of vibration response leading to a larger damping ratio [33]. The tester is the vibration inducer and the energy absorber. The damping ratio increases slightly for the rising mass and amplitude. However, compared to the real damping ratio from the ambient tests, both heel-drop and jumping tests overestimate the value for containing the true damping and the transmission of vibration energy to other structural components [20]. Specifically, the damping ratio owing to single-person heel-drop and jumping tests at the central floor is 1.24 times and 1.35 times of the real damping value. Based on the measurements, the paper suggests a reduction factor of 0.7 for the damping ratio of the $\mathrm{CHW}$ slab under single-person heel-drop or jumping excitations.

\section{Vibration Serviceability Assessment}

The frequency threshold, acceleration threshold, and person perception suggested by current codes are taken to give a comprehensive vibration assessment for the CHW slab.

5.1. Frequency Threshold Criterion. The frequency threshold aims to control the frequency higher than a certain value to avoid the floor fundamental frequency falling into the range of human activities. It plays a key role in vibration control. The Chinese Code GB 50010-2010 recommends that the fundamental frequency of large-span public buildings should be larger than $3 \mathrm{~Hz}$. In British codes CCIP-016, BS6472-1, and ISO 10137, they divide the floors into the high-frequency floor and low-frequency floor with a boundary ranging from 8 to $10 \mathrm{~Hz}$. The frequency threshold recommended by AISC DG 11 is $9 \mathrm{~Hz}$. The fundamental frequency of the CHW slab is $6.25 \mathrm{~Hz}$, the value only meets the requirement of GB 50010-2010, as to American and British codes, and the floor is sensitive to excitation.

5.2. Acceleration Threshold Criteria. The traditional frequency threshold cannot reflect the diversity of human excitations, high-order components, and the influence of the damping ratio. The amplitude threshold is more reliable for vibration serviceability assessment, among which the acceleration threshold is the most widely used. The Chinese code [17] only stipulates the acceleration threshold for one person walking which is not suitable for impulsive excitations like heel-drop and jumping. ISO 10137 and AISC DG 11 are chosen to assess the vibration performance of the CHW slab under heel-drop and jumping activities.

ISO 10137 uses the RMS acceleration value as vibration intensity and gives a base curve considering frequencyweighting functions. Different multiplying factors to the base curve are suggested considering building functions and durations. Multiplying factors to the base curve are between 60 and 128 for open office buildings under impulsive excitation. The $10 \mathrm{~s}$ RMS acceleration suggested by ISO for comfort criterion is used for the CHW SLAB. Figure 11 shows the peak $10 \mathrm{~s}$ RMS accelerations measured from the heel-drop tests in the range of 0.5 to 1 times the value of the

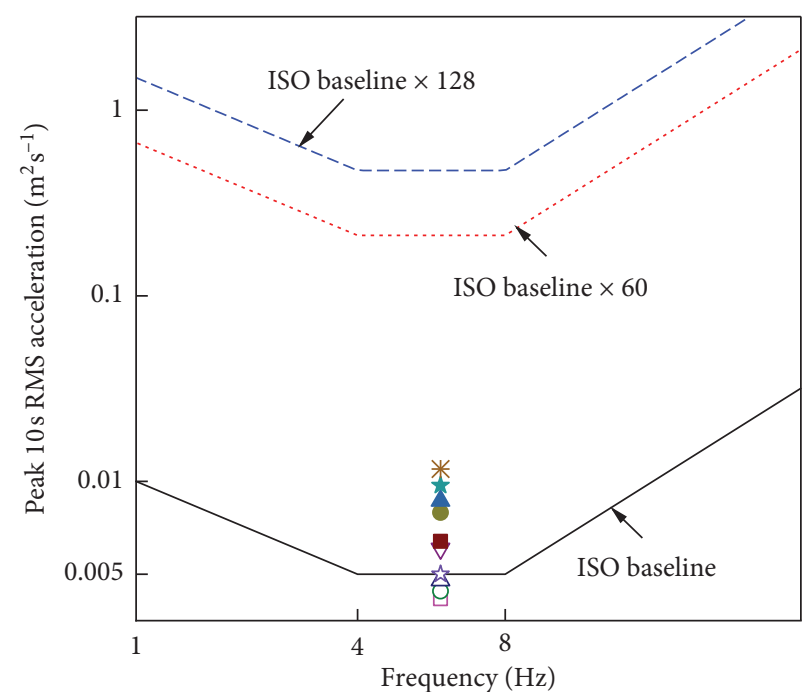

$$
\begin{array}{ll}
5 \text { persons (5ps) } & \\
\square \text { Heel-drop (1p) } & \text { Jumping (1p) } \\
\bigcirc \text { Heel-drop (2ps) } & \text { Jumping (2ps) } \\
\triangle \text { Heel-drop (3ps) } & \star J u m p i n g ~(3 p s) \\
\star \text { Heel-drop (4ps) } & \text { * Jumping (4ps) } \\
\nabla \text { Heel-drop (5ps) } &
\end{array}
$$

FIgURE 11: Vibration serviceability assessment by ISO-10137.

base curve. Jumping is the most severe human-induced excitation. However, the multiplying factors merely range from 1.5 to 3 , and the multiplying factors are far below the range of 60 to 128 suggested by ISO for impulsive excitation. The CHW slab can easily satisfy the threshold of ISO 10137; meanwhile, the code is too conservative for the vibration evaluation of the CHW slab. The paper suggests a multiplying factor of 10 to the base curve for vibration evaluation of the $\mathrm{CHW}$ slab under impulsive excitation.

AISC DG 11 also takes the ISO base curve with a multiplying factor. Differently, AISC takes the peak acceleration threshold for vibration serviceability. A multiplying factor of 10 is recommended for the residential and office buildings and 30 for the shopping malls and dance halls. For rhythmic activities and outdoor footbridges, the multiplying factor is 100. Figure 12 shows that only five-person heeldrop excitation results exceed the bottom line of the residential and office buildings (multiplier 10). All results obtained from jumping tests are in the range of multiplying factors between 10 and 30, which satisfy the request for shopping malls and dance halls. The values suggested by AISC are more reasonable than by ISO; however, the measurements are much lower than the multiplying factor of 100 for rhythmic activities. The paper suggests a multiplying factor of 60 for vibration evaluation of the $\mathrm{CHW}$ slab under impulsive excitation.

5.3. Human Perceptions. Humans are the user and receiver of the floor system. Note that the frequency threshold and the acceleration threshold cannot reflect the diversity of person perception, and person perceptions during the tests were recorded by a questionnaire. Human sensitivity is 


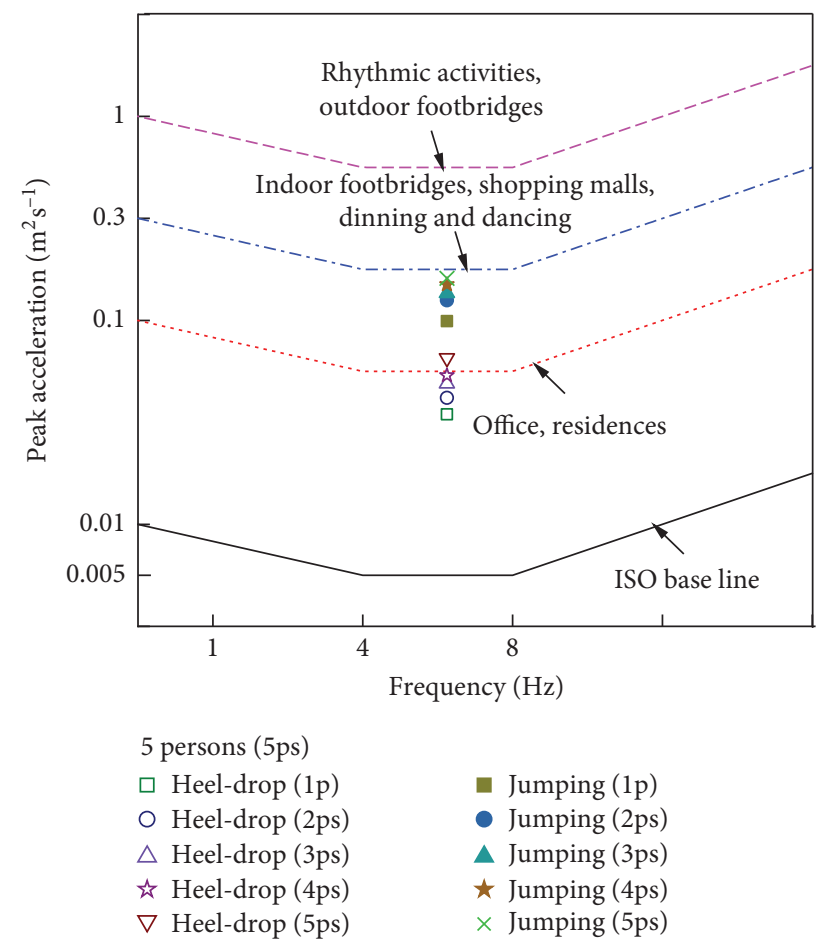

FIGURE 12: Vibration serviceability assessment by AISC DG-11.

divided into four groups: A for senseless vibration, B for slight vibration, $\mathrm{C}$ for medium vibration, and $\mathrm{D}$ for strong vibration. The statistics include 10 persons, five of whom participated in the test. Most people felt senseless vibration during heel-drop tests, and most people felt slight vibration during jumping tests (Table 6). The peak acceleration boundary between senseless vibration and slight vibration is about $0.05 \mathrm{~mm}^{2} \mathrm{~s}^{-1}$. During the whole tests, no one felt uncomfortable, and the CHW slab showed good vibration performance. Meanwhile, the paper suggests the peak acceleration threshold of $0.05 \mathrm{~mm}^{2} \mathrm{~s}^{-1}$ for the slight vibration of the CHW slab under impulsive excitation.

\section{Analytical Prediction for Natural Frequencies}

Natural frequencies are critical dynamical properties of a floor. However, the assumption of simply supported beam or plate models is not suitable for a complicate floor like the CHW slab. As a large-span floor system constrained by dense columns and deep beams, the natural frequency formula of the CHW slab can be derived using the Rayleigh-Ritz energy method with four built-in edges.

6.1. Simplified Calculation and Basic Assumptions. The $\mathrm{U}$-shaped steel-concrete composite hollow waffle floor is a three-dimensional composite floor system; to simplify the calculation, the beams with openings below the RC slab are equivalent to solid beams with the same flexural rigidity (Figure 13).

Basic assumptions are used to predict natural frequency formula as follows:
TABLE 6: Results of questionnaires.

\begin{tabular}{lcccccc}
\hline Excitation & Testers & $\alpha_{\text {peak }}\left(\mathrm{mm}^{2} \mathrm{~s}^{-1}\right)$ & $\mathrm{A}$ & $\mathrm{B}$ & $\mathrm{C}$ & $\mathrm{D}$ \\
\hline \multirow{4}{*}{ Heel-drop } & 1 person & 30.64 & 10 & 0 & 0 & 0 \\
& 2 persons & 37.33 & 9 & 1 & 0 & 0 \\
& 3 persons & 43.80 & 8 & 2 & 0 & 0 \\
& 4 persons & 47.78 & 7 & 3 & 0 & 0 \\
& 5 persons & 51.76 & 7 & 3 & 0 & 0 \\
\hline \multirow{4}{*}{ Jump } & 1 person & 74.20 & 5 & 5 & 0 & 0 \\
& 2 persons & 94.84 & 4 & 6 & 0 & 0 \\
& 3 persons & 109.11 & 3 & 7 & 0 & 0 \\
& 4 persons & 122.66 & 2 & 8 & 0 & 0 \\
& 5 persons & 133.15 & 0 & 9 & 1 & 0 \\
\hline
\end{tabular}

(i) The normal strains perpendicular to the neutral plane are negligible according to the thin plate theory [39]. Namely, the vertical displacement of the beams and plate along the thickness direction is equal to the deflection $w$.

(ii) There is no relative displacement between the beam and plate.

(iii) The web member is simplified as a concentrated mass.

6.2. Free Vibration of Isotropic Plates. The mode function meeting the boundary conditions of four clamped edges is

$$
w(x, y)=a_{m n}\left(1-\cos \frac{2 m \pi x}{a}\right)\left(1-\cos \frac{2 n \pi y}{b}\right),
$$

where $a_{m n}$ is a constant; $a$ and $b$ are the floor dimensions; and $m$ and $n$ are the wavenumbers of a half sinusoid along the $x$ and $y$ directions (Figure 14). 


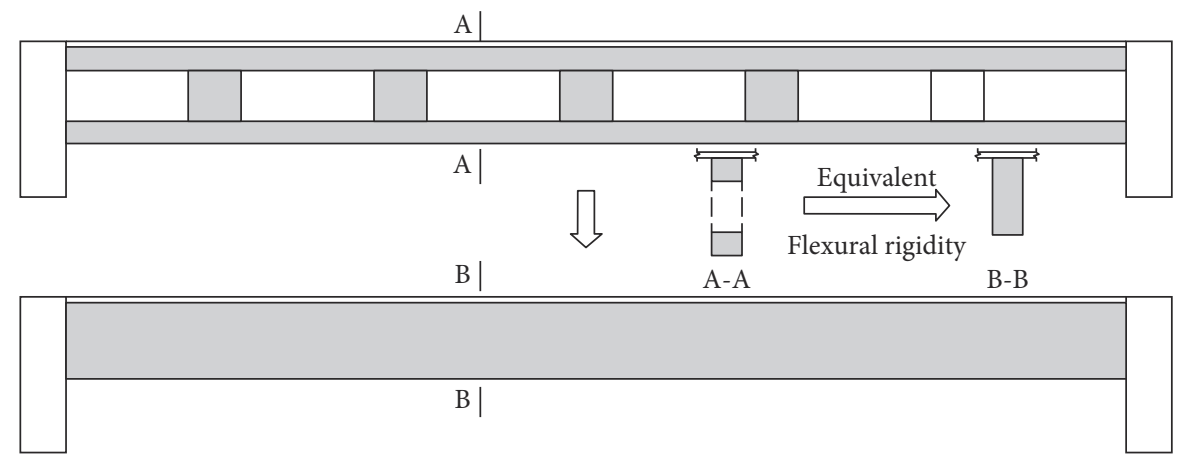

FIGURE 13: Stiffness equivalent method for beams.

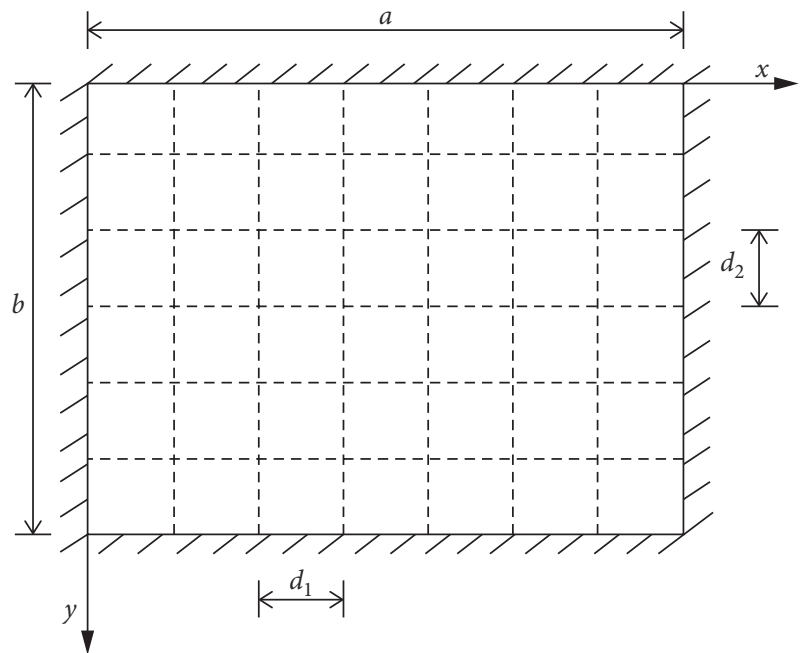

FIGURE 14: Floor with four built-in edges.

Assuming $A_{i}=a_{m n}\left(1-\cos \left(2 m \pi x_{i} / a\right)\right)$ and $A_{j}=a_{m n}(1$ $\left.-\cos \left(2 n \pi y_{j} / b\right)\right)$, the deflection at location $x=x_{i}$ parallel to the $y$-direction can be expressed by

$$
w\left(x_{i}, y\right)=A_{i}\left(1-\cos \frac{2 n \pi y}{b}\right) .
$$

The deflection at location $y=y_{i}$ parallel to the $x$ direction can be expressed by

$$
w\left(x, y_{j}\right)=A_{j}\left(1-\cos \frac{2 m \pi x}{a}\right)
$$

The maximum potential energy of the floor $U_{\max }$ contains the maximum potential energy of equivalent cross beam system $U_{B \max }$ and RC slab $U_{S \max }$ as follows:

$$
U_{\text {max }}=U_{B \text { max }}+U_{S \text { max }} \text {. }
$$

The maximum potential energy of the equivalent cross beam system can be expressed as

$$
\begin{aligned}
U_{B \max } & =\sum_{j=1}^{r} \frac{D_{1}}{2} \int_{0}^{a}\left(\frac{\partial^{2} w}{\partial x^{2}}\right)_{y=y_{j}}^{2} \mathrm{~d} x+\sum_{i=1}^{s} \frac{D_{2}}{2} \int_{0}^{b}\left(\frac{\partial^{2} w}{\partial y^{2}}\right)_{x=x_{i}}^{2} \mathrm{~d} y \\
& =4 \pi^{4}\left(\frac{m^{4} D_{1}}{a^{3}} \sum_{j=1}^{r} A_{j}^{2}+\frac{n^{4} D_{2}}{b^{3}} \sum_{i=1}^{s} A_{i}^{2}\right),
\end{aligned}
$$

where $D_{1}$ and $D_{2}$ are the flexural rigidity along the $x$ and $y$ directions.

Since the distance between each beam is equal, the following formulas can be expressed as

$$
\begin{aligned}
& \left\{\begin{array}{l}
A_{i}=a_{m n}\left(1-\cos \frac{2 m \pi x_{i}}{a}\right)=a_{m n}\left(1-\cos \frac{2 m \pi i d_{1}}{(s+1) d_{1}}\right)=a_{m n}\left(1-\cos \frac{2 m \pi}{s+1} i\right), \\
A_{j}=a_{m n}\left(1-\cos \frac{2 n \pi y_{i}}{b}\right)=a_{m n}\left(1-\cos \frac{2 n \pi j d_{2}}{(r+1) d_{2}}\right)=a_{m n}\left(1-\cos \frac{2 n \pi}{r+1} j\right),
\end{array}\right. \\
& \left\{\begin{array}{l}
\sum_{i=1}^{s}\left(1-\cos \frac{2 m \pi}{s+1} i\right)^{2}=\frac{3(s+1)}{2}\left(m<\frac{s+1}{2}\right), \\
\sum_{j=1}^{r}\left(1-\cos \frac{2 n \pi}{r+1} j\right)^{2}=\frac{3(r+1)}{2}\left(n<\frac{r+1}{2}\right),
\end{array}\right.
\end{aligned}
$$


where $r$ and $s$ are the numbers of the equivalent beam and $d_{1}$ and $d_{2}$ are the distance between each beam along the $x$ and $y$ directions.

Substituting equations (10) into (9), the maximum potential energy of the equivalent cross beam system can be expressed as

$$
U_{B \max }=6 a_{m n}^{2} \pi^{4}\left[\frac{m^{4} D_{1}}{a^{3}}(r+1)+\frac{n^{4} D_{2}}{b^{3}}(s+1)\right] .
$$

The maximum potential energy of equivalent cross beam system is given by

$$
\begin{aligned}
U_{S \max } & =\frac{D_{s}}{2} \int_{0}^{a} \int_{0}^{b}\left(\frac{\partial^{2} w}{\partial x^{2}}+\frac{\partial^{2} w}{\partial y^{2}}\right)^{2} \mathrm{~d} x \mathrm{~d} y \\
& =2 a_{m m}^{2} \pi^{4} a b D_{s}\left(\frac{3 m^{4}}{a^{4}}+\frac{3 n^{4}}{b^{4}}+\frac{2 m^{2} n^{2}}{a^{2} b^{2}}\right),
\end{aligned}
$$

where $D_{s}$ is the flexural rigidity of the slab.

The maximum kinetic energy of the floor $T_{\max }$ include the maximum kinetic energy of the upper beams and lower beams $T_{B \max }$, web members $T_{W \max }$, and RC floor $T_{S \max }$ as follows:

$$
T_{\max }=T_{B \max }+T_{W \max }+T_{S \max } .
$$

The maximum kinetic energy of the upper beams and lower beams considering equation (10) can be written as

$$
\begin{aligned}
T_{B \max } & =\left[\frac{M_{1}}{2 a} \sum_{j=1}^{r} \int_{0}^{a} w^{2}\left(x, y_{i}\right) \mathrm{d} x+\frac{M_{2}}{2 b} \sum_{i=1}^{s} \int_{0}^{b} w^{2}\left(x_{i}, y\right) \mathrm{d} y\right] \omega_{m n}^{2} \\
& =\frac{9}{8} a_{m n}^{2}\left[M_{1}(r+1)+M_{2}(s+1)\right] \omega_{m n}^{2},
\end{aligned}
$$

where $M_{1}$ and $M_{2}$ are the total masses of the upper beam and lower beam parallel to the $x$ direction and $y$ direction and $\omega_{m n}$ is the natural frequency of the floor system.

The maximum kinetic energy of the web members using equation (10) is

$$
\begin{aligned}
T_{W \max } & =\left[\frac{M_{3}}{2} \sum_{i=1}^{s} \sum_{j=1}^{r} w^{2}\left(x_{i}, y_{i}\right)\right] \omega_{m n}^{2} \\
& =\frac{9}{8} a_{m n}^{2} M_{3}(s+1)(r+1) \omega_{m n}^{2},
\end{aligned}
$$

where $M_{3}$ is the mass of a web member.

The maximum kinetic energy of the RC floor using equation (10) is

$$
T_{P \max }=\frac{\omega_{m n}^{2}}{2} \int_{0}^{a} \int_{0}^{b} \overline{m_{S}} w^{2}(x, y) \mathrm{d} x \mathrm{~d} y=\frac{9}{8} a_{m n}^{2} \omega_{m n}^{2} M_{S}
$$

where $M_{S}$ is the total mass of the slab and $\overline{m_{S}}$ is the mass per unit area of the slab.

Thus, $\omega_{m n}$ can be obtained by setting

$$
\frac{\partial}{\partial a_{m m}}\left(U_{\max }-T_{\max }\right)=0 .
$$

Substituting the maximum potential energy in equations (8) and (13) into equation (17), the natural frequencies of the CHW slab can be expressed as

$$
\omega_{m n}=\frac{4 \pi^{2}}{3} \sqrt{\frac{3\left[\left(m^{4} D_{1} / a^{3}\right)(r+1)+\left(n^{4} D_{2} / b^{3}\right)(s+1)\right]+a b}{\left[M_{1}(r+1)+M_{2}(s+1)+M_{3}(s+1)(r+1)+M_{P}\right]}},
$$

The natural frequencies of the CHW slab can be calculated by taking different $m$ and $n$ values. For instance, $m=1$ and $n=2$ denote only one waveform along the $x$ direction and two waveforms along the $y$ direction. The frequencies of the first three modes calculated by equation (18) are $6.05 \mathrm{~Hz}, 9.98 \mathrm{~Hz}$, and $13.15 \mathrm{~Hz}$, which are $96.8 \%$, $94.7 \%$, and $93.7 \%$ of the values obtained by EMA. The small error between the two verifies the accuracy of theoretical formulas.

\section{Summary and Conclusions}

The vibration performance of an innovative long-span U-shaped steel-concrete composite hollow waffle floor is $\{m<(s+1) / 2, n<(r+1) / 2\}$.

studied based on experimental and theoretical analysis. The conclusions and suggestions are described as follows:

(i) The CHW slab shows the behavior of a plate in free vibration with low frequency $(6.25 \mathrm{~Hz})$ and low damping ratio $(2.35 \%)$. The mode shapes and frequencies from the OMA and EMA method match well.

(ii) The measurements from heel-drop and jumping tests are accurate for frequency prediction. However, both heel-drop and jumping tests overestimate the value compared to the real damping ratio from the OMA method. The paper suggests a reduction factor of 0.7 for the damping ratio of the CHW slab under single person heel-drop or jumping excitations. 
(iii) Jumping is much more severe than heel-drop with the same person undertaking the tests at the floor center. The vibration response increases notably with the rising tester numbers. The vibration response weakens from the center to the edge. When the distance to the floor center is the same, larger vibration happens along the long span with the same distance from the central floor.

(iv) The vibration performance satisfies ISO maximum $10 \mathrm{~s}$ RMS acceleration and AISC peak acceleration threshold, and no one felt uncomfortable during the tests. However, the threshold values are too conservative; the paper suggests a multiplying factor of 10 for vibration evaluation of the CHW slab by the threshold of the peak $10 \mathrm{~s}$ RMS acceleration and a multiplying factor of 60 by the threshold of peak acceleration under impulsive excitation.

(v) The natural frequency formula for the CHW slab derived by the energy method is in good agreement with the test results. Meanwhile, it is also suitable for waffle slabs.

\section{Data Availability}

The data used to support the findings of this study are included within the article.

\section{Conflicts of Interest}

The authors declare that they have no conflicts of interest.

\section{Acknowledgments}

This work was supported by the National Natural Science Foundation of China (grant number: 51374212).

\section{References}

[1] Y.-T. Guo, M.-X. Tao, X. Nie, and J.-S. Fan, "Rigidity and moment distribution of steel-concrete composite waffle floor systems considering the spatial effect," Engineering Structures, vol. 143, pp. 498-510, 2017.

[2] M. Lasheen, A. Shaat, and A. Khalil, "Numerical evaluation for the effective slab width of steel-concrete composite beams," Journal of Constructional Steel Research, vol. 148, pp. 124-137, 2018.

[3] A. Pavic, P. Reynolds, P. Waldron, and K. Bennett, "Dynamic modelling of post-tensioned concrete floors using finite element analysis," Finite Elements in Analysis and Design, vol. 37, no. 4, pp. 305-323, 2001.

[4] S. L. Fernanda, K. Moacir, S. Osama, M. Zacarias, and P. Chamberlain, "Experimental and analytical study of vibration parameters in waffle concrete slabs," Engineering Structures, vol. 199, Article ID 109593, , 2019.

[5] X. Zhou, L. Cao, Y. F. Chen, J. Liu, and J. Li, "Experimental and analytical studies on the vibration serviceability of prestressed cable RC truss floor systems," Journal of Sound and Vibration, vol. 361, pp. 130-147, 2016.

[6] Q. An, Q. Ren, H. Liu, X. Yan, and Z. Chen, "Dynamic performance characteristics of an innovative cable supported beam structure-concrete slab composite floor system under human-induced loads," Engineering Structures, vol. 117, pp. 40-57, 2016.

[7] C. M. Abeysinghe, D. P. Thambiratnam, and N. J. Perera, "Dynamic performance characteristics of an innovative hybrid composite floor plate system under human-induced loads," Composite Structures, vol. 96, pp. 590-600, 2013.

[8] C. A. Jones, P. Reynolds, and A. Pavic, "Vibration serviceability of stadia structures subjected to dynamic crowd loads: a literature review," Journal of Sound and Vibration, vol. 330, no. 8, pp. 1531-1566, 2011.

[9] S. Živanović, A. Pavic, and P. Reynolds, "Vibration serviceability of footbridges under human-induced excitation: a literature review," Journal of Sound and Vibration, vol. 279, no. 1-2, pp. 1-74, 2005.

[10] K. A. Salyards and Y. Hua, "Assessment of dynamic properties of a crowd model for human-structure interaction modeling," Engineering Structures, vol. 89, pp. 103-110, 2015.

[11] R. Parnell, B. W. Davis, and L. Xu, "Vibration performance of lightweight cold-formed steel floors," Journal of Structural Engineering, vol. 136, no. 6, pp. 645-653, 2010.

[12] A. Ebrahimpour and R. L. Sack, "A review of vibration serviceability criteria for floor structures," Computers \& Structures, vol. 83, no. 28-30, pp. 2488-2494, 2005.

[13] E. M. Sarah and R. E. Bruce, "Guidelines to minimize floor vibration from building occupants," Journal of Structural Engineering, vol. 120, no. 2, pp. 507-526, 1994.

[14] P. Reynolds and A. Pavic, "Effects of false floors on vibration serviceability of building floors. I: modal properties," Journal of Performance of Constructed Facilities, vol. 17, no. 2, pp. 75-86, 2003.

[15] British Standards Institution, to Evaluation of Human Exposure to Vibration in Buildings-Part 1: Vibration Sources Other than Blasting, British Standards Institution, no. BS6472-1, Guide, London, UK, 2008.

[16] China Academy of Building Research, GB 50010-2010 Code for Design of Concrete Structures, National Design Code of Chinese, Beijing, China, 2010, in Chinese.

[17] China Academy of Building Research, JGJ3-2010 Technical Specification for Concrete Structures of Tall Building, Beijing, China, in Chinese.

[18] International Standards Organization ISO 10137, Bases for Design of Structures-Serviceability of Buildings and Walkways against Vibration, International Standards Organization, Geneva, Switzerland, 2007.

[19] The Concrete Centre, CCIP-016, A Design Guide for Footfall Induced Vibration of Structures, The Concrete Centre, London, UK, 2005.

[20] American/Canada Institute of Steel Construction (AISC/ CISC), Steel Design Guide Series No. 11: Floor Vibrations Due to Human Activity, American/Canada Institute of Steel Construction (AISC/CISC),, Chicago, IL, USA, 2003.

[21] C. J. Middleton and J. M. W. Brownjohn, "Response of high frequency floors: a literature review," Engineering Structures, vol. 32, no. 2, pp. 337-352, 2010.

[22] J. Chen, R. Xu, and M. Zhang, "Acceleration response spectrum for predicting floor vibration due to occupant walking," Journal of Sound and Vibration, vol. 333, no. 15, pp. 3564-3579, 2014.

[23] H. Luan, K. Ma, Y. Qin, Z. Chen, and Y. Wei, "Investigation of the structural behavior of an innovative steel open-web floor system," International Journal of Steel Structures, vol. 17, no. 4, pp. 1365-1378, 2017.

[24] Z. P. Chen, G. Wu, D. C. Feng, and K. J. Ma, "Numerical study of the static and dynamic characteristics of reinforced 
concrete cassette structures for high-rise buildings," Tall and Special Buildings, vol. 28, no. 3, p. 1574, 2019.

[25] R. Rijal, B. Samali, R. Shrestha, and K. Crews, "Experimental and analytical study on dynamic performance of timberconcrete composite beams," Construction and Building $M a$ terials, vol. 75, pp. 46-53, 2015.

[26] L. Hu and K. J. Ma, "Test and research of comfortable degree of structure of high strength bolts connected U-shaped steel plate-concrete composite open-web sandwich floor," Journal of Building Structures, vol. 33, no. 7, pp. 70-75, 2012.

[27] R. Brincker and C. E. Ventura, Introduction to Operational Modal Analysis, Chichester, UK, 2015.

[28] ABAQUS, Analysis User's Manual, Version 6.12-1, ABAQUS Inc., Palo Alto, CA, USA, 2012.

[29] F. Pioldi, R. Ferrari, and E. Rizzi, "Output-only modal dynamic identification of frames by a refined FDD algorithm at seismic input and high damping," Mechanical Systems and Signal Processing, vol. 68-69, pp. 265-291, 2016.

[30] A. C. Altunisik, A. Bayraktar, B. Sevim, and H. Ozdemir, "Experimental and analytical system identification of Eynel arch type steel highway bridge," Journal of Constructional Steel Research, vol. 67, no. 12, pp. 1912-1921, 2011.

[31] R. Brincker, C. Ventura, and P. Andersen, "Damping estimation by frequency domain decomposition," in Proceedings of the 19th International Modal Analysis Conference (IMAC), vol. 1, pp. 698-703, Kissimmee, FL, USA, 2000.

[32] P. Górski, "Dynamic characteristic of tall industrial chimney estimated from GPS measurement and frequency domain decomposition," Engineering Structures, vol. 148, pp. 277-292, 2017.

[33] R. W. Clough and J. Penzien, Dynamics of Structures, Computers \& Structures, Berkeley, CA, USA, 3rd edition, 2003.

[34] V. Racic and A. Pavic, "Mathematical model to generate asymmetric pulses due to human jumping," Journal of Engineering Mechanics, vol. 135, no. 10, pp. 1206-1211, 2009.

[35] S. Zivanovic, A. Pavic, and P. Reynolds, "Human-structure interaction in footbridges," Proceedings of the Institution of Civil Engineers-Bridge Engineering, vol. 158, no. 4, pp. 165177, 2005.

[36] A. Ebrahimpour, Modeling spectator induced dynamic loads, Ph.D. thesis, University of Idaho, Moscow, ID, USA, 1987.

[37] B. R. Ellis and T. Ji, "The response of structures to dynamic crowd loads," BRE Digest, vol. 426, 2004.

[38] L. Guo, T. J. Tian, and J. Chen, "Determination of the dynamic load factors for crowd jumping using motion capture technique," Engineering Structures, vol. 174, pp. 1-9, 2018.

[39] S. Timoshenko and S. Woinowsky, Theory of Plates and Shells, McGraw-Hill, New York, NY, USA, 2nd edition, 1959. 